\title{
Entre cuatro ruedas: lógica automovilistica y barrios semicerrados en la ciudad de Cali (Colombia) ${ }^{1}$
}

\author{
Francisco Adolfo García Jerez ${ }^{2}$ \\ Universidad del Valle, Colombia \\ adolfo.garcia@correounivalle.edu.co \\ Recibido: 29 de enero de 2017 \\ Aceptado: 12 de agosto de 2017 \\ Disponible en línea: 30 de junio de 2018
}

1 Artículo de investigación. Este texto es producto de la investigación titulada "Planificación urbanística, hábitos y representaciones sobre la movilidad socio-espacial: un análisis de la motilidad en dos barrios de Cali” (C.I. 6166), proyecto que fue financiado por la Universidad del Valle (Cali, Colombia).

2 Doctor en Antropología Social y Cultural, Universidad Pablo de Olavide (España). Profesor del Departamento de Ciencias Sociales, Universidad del Valle (Colombia). 


\title{
Entre cuatro ruedas: lógica automovilistica y barrios semicerrados en la ciudad de Cali (Colombia)
}

\section{Resumen}

Partiendo de la premisa de que el automóvil ha transmutado sustancialmente la vida urbana, este artículo tiene como objetivo indagar sobre la dimensión ideacional que los residentes de dos barrios de la ciudad colombiana de Cali poseen acerca de su movilidad y de los medios de transporte. Para ello, el análisis se basará en una interpretación durkheimiana de la representación social, entendiendo que esta última no es una dimensión autónoma que se configura de espalda a la realidad fáctica sino, muy al contrario, que esta interactúa, estructura y es estructurada por las prácticas sociales. Tres son las representaciones que, finalmente, confluirán en la configuración de una lógica automovilística en los residentes de los dos barrios de clases medias analizados, y que podrian sintetizarse del siguiente modo: la del desiderátum de la movilidad sostenible, la del automóvil como dispositivo eficiente y la de la mixtificación de la conducción.

Palabras clave: automóvil; movilidad cotidiana; representaciones sociales; clases medias; Cali

\section{In four wheels: automotive logic and semi- closed neighborhoods in Cali (Colombia)}

\begin{abstract}
Based on the premise that the car has substantially transformed urban life, the aim of this article is to investigate the dimension of the ideas that residents of two neighborhoods in Cali (Colombia) have about their mobility and means of transportation. For this purpose, the analysis will be grounded on a Durkheim-based interpretation of social representation, understanding that this is not an autonomous dimension configured with its back turned against factual reality; rather, it interacts, structures, and is structured by social practices. Three representations will finally converge in the configuration of automotive logic in the residents of the two middle-class neighborhoods analyzed, which could be summarized as follows: the desideratum of sustainable mobility, the automobile as an efficient device, and the mystification of driving.
\end{abstract}

Keywords: automobile; daily mobility; social representations; middle classes; Cali

\section{Entre quatro pneus: lógica automotiva e bairros semifechados na cidade de Cali (Colômbia)}

\section{Resumo}

A partir da premissa que o automóvel transmudou substancialmente a vida urbana, este artigo visa investigar a dimensão ideacional que os residentes de dois bairros da cidade colombiana de Cali possuem sobre a mobilidade e os meios de transporte. Para isso, a análise vai ser baseada em uma interpretação durkhemniana da representação social, entendendo que esta não é uma dimensão autónoma configurada de volta à realidade fatual, mas, pelo contrário, que interage, estrutura e é estruturada pelas práticas sociais. Três são as representações que, por fim, confluem na configuração de uma lógica automobilística nos moradores dos dois bairros de camadas meias analisados, as quais poderiam se sintetizar do modo: a do desiderátum da mobilidade sustentável, a do automóvel como dispositivo eficiente e a da mistificação do dirigimento.

Palavras-chave: automóvel; mobilidade quotidiana; representações sociais; camadas meias; Cali 


\section{La lógica automovilística}

Si la modernidad se fundamentó en algún aspecto significativo más allá de la noción de racionalidad fue en la idea de velocidad -la cual atravesaba los modos de producción económica bajo el auspicio de la lógica fordista-, como en la reconceptualización de la movilidad a partir de la entrada en juego de nuevos medios de transporte impulsados por el motor a vapor y de explosión. De hecho, fue el manifiesto "Le Futurisme" del poeta italiano Tommaso Marinetti, publicado por primera vez en Le Figaro en el año 1909, una de las primeras proclamas que mejor certificó la velocidad como el gran baluarte del cambio de mentalidad producido a comienzos del siglo XX. Con el paso de los años y la sofisticación y la popularización del automóvil, este comenzó a representar mejor que cualquier otro dispositivo el arquetipo de la modernidad. A la idea de velocidad, se le sumó la de comodidad y distinción, convirtiéndolo en un paradigma de nuestra sociedad capaz de proyectar los principios vertebradores de la misma: independencia, individualidad y rapidez (Giucci, 2007; Sennet, 2007). La rápida expansión del automóvil se debió tanto a las estrategias empresariales encarnadas en las de la compañia Ford como a las politicas públicas, las cuales tenían como fin reconvertir el sistema de transporte y movilidad existente favoreciendo la construcción de vías por las que pudieran circular esas nuevas máquinas (Zeller, 2011).

Lo cierto es que este proceso en el que queda configurado institucionalmente un paradigma de movilidad basado en la hegemonía del vehículo particular motorizado conllevó a su vez, y de un modo simultáneo, a la conformación de una "cultura automovilística" ${ }^{3}$ (Sheller, 2004; Urry, 2004) que, en palabras de Motavalli (2001), se encarnará en última instancia en una "automobile addiction" interiorizada por amplios segmentos de la sociedad. Roland Barthes situó al automóvil como el nuevo objeto fetiche de la sociedad contemporánea cuando afirmaba que este "es en nuestros dias el equivalente bastante exacto de las grandes catedrales góticas" (1999, p. 92); convirtiéndose en palabras de Anta en un "símbolo político: un sistema de múltiples niveles

\footnotetext{
Para más información acerca de la discusión del término "cultura automovilística" en el actual contexto global se recomienda consultar la web Mobile Lives Forum, en su edición titulada "What future for automobiles?", en particular el video Thinking the future of car mobility. Recuperado de http://en.forumviesmobiles.org/video/2016/09/20/thinkingfuture-car-mobility-3303
} 
que muestra desde criterios de identidad hasta diferentes arenas de dominio y control" (2015, p. 101). Y dado que el ideal es consumar un desplazamiento bajo pautas de racionalidad que implique la menor inversión de tiempo posible, el automóvil se ha convertido en el dispositivo más funcional por cuanto permite seleccionar rutas, gozar de una alta disponibilidad y consumar el trayecto en una velocidad óptima; ello desde la elección individual. Parafraseando a Hagman (mencionado en Ureta, 2009), el automóvil nos libera de los límites espacio-temporales, de ahí que hasta el momento ningún sistema de transporte urbano haya podido competir con este.

Desde hace unas décadas esta "cultura automovilística" también se observa en América Latina. Tal y como afirma un informe del BBVA, desde el año 2000 el parque automotriz en la región ha experimentado un rápido crecimiento pasando de 42,1 millones de unidades a 65,8 millones en 2009 (BBVA Research, 2010, p. 4). Frente a esta situación de automovilización, muchos gobiernos locales han ido adoptando algunas medidas para paliar los problemas derivados de ese incremento, entre las cuales destacan la inversión en vías con el fin de ampliar la capacidad para el tránsito de vehículos particulares y/o la mejoría de los sistemas de transporte público (Pardo, 2009). Con respecto a la ciudad de Cali, esta no ha sido ajena a tal fenómeno, ya que en los últimos lustros también ha experimentado un incremento de su parque automotor al pasar de 373936 automóviles en el 2005 a 504653 en el 2010. Esto significó un incremento del $35 \%$. De hecho, es una de las ciudades en Colombia donde los habitantes se movilizan más en vehículos privados motorizados, con un $38 \%$; a diferencia de Cartagena de Indias con un $30 \%$, de Medellín con un $24 \%$ o de Bogotá con un 19 \% (Red de Ciudades Cómo Vamos, 2015). Con respecto a su parque automovilístico, la mayoria se concentra en aquellas zonas donde residen las clases medias y altas (Steer Davies Gleave, 2015, p. 133), sectores fundamentalmente mestizos y blancos.

Así pues, y dando por válida la existencia en la sociedad latinoamericana y colombiana de un incipiente proceso de "cultura automovilística", en el presente artículo me he interesado por las representaciones sociales que poseen los residentes de dos barrios de nueva construcción y destinados a las clases medias con respecto a su movilidad y al rol de 
esas representaciones en los modos y en la lógica de desplazamientos. Obviamente, la premisa desde la cual parto es que las representaciones sociales son una pieza fundamental en el mantenimiento del actual modelo de movilidad, puesto que de algún modo implementan o se articulan tanto con la oferta como con las prácticas de movilidad existentes; de ahí que trate de conocer cómo ese nuevo segmento social de clase media interpreta y se apropia de esa oferta. Por todo ello, esta propuesta investigativa debería inscribirse en los actuales debates sobre el importante rol que juegan los medios de transporte en relación con las dinámicas sociales y urbanas (Sheller y Urry, 2000).

En efecto, me he enfocado en los residentes de dos barrios semicerrados de nueva construcción destinados a las clases medias caleñas (los barrios La Hacienda y Valle del Lili) y he aplicado entrevistas semiestructuradas a 20 residentes (10 mujeres y 10 hombres), así como sesiones de observación directa en uno de los barrios (con motivo de un anterior proyecto vinculado a la misma temática en 2013) y flotante en ambos barrios durante el año 2015; también realicé una encuesta a 148 personas (58 hombres y 90 mujeres) de una población estimada de 9142 vecinos, de los cuales 55 residían en el barrio Valle del Lili (los residentes se estimaron en 3383), y 93 en La Hacienda (su población era de 5759). La encuesta fue de tipo muestreo estratificado con un nivel de confianza del $95 \%$ y un margen de error del $8 \%$. Tanto para las entrevistas como para la encuesta la población seleccionada debía ser residente de una de las vecindades y tener una edad entre los 20 y 65 años aproximadamente. Con respecto a los resultados de las entrevistas, los clasifiqué en cuatro categorias: hábitos de movilidad cotidiana, experiencias de movilidad, representaciones sobre los medios de transporte y grado de satisfacción. Si bien los extractos incluidos no poseen un carácter probabilístico ni cuantitativamente representativo, estimo que, en cualquier caso, estos pueden ayudar tanto a ilustrar y corroborar ciertas tendencias observadas, como a captar determinadas subjetividades sobre la movilidad cotidiana que se han ido configurando en la ciudad de Cali.

Por último, además de señalar que para llevar a cabo esta investigación conté con la colaboración de un equipo de monitores estudiantes de Sociología de la Universidad del Valle (a los que agradezco muy 
sinceramente su entusiasmo y buen hacer), he de reconocer que, como investigador principal, tras la finalización del trabajo de campo me matriculé en una academia de conducción en la que obtuve finalmente la licencia; ello con el fin de reconocer en primera persona las lógicas de la práctica de la automoción en la ciudad. Era la primera vez que me ponía frente al volante de un automóvil. Así mismo, tengo la impresión de que mi condición de europeo, así como las de haber residido fundamentalmente en ciudades compactas y densas y la de ser un fiel usuario de medios de transporte colectivos han potenciado, por un lado, mi extrañamiento y, por otro, la toma de una perspectiva (a veces excesivamente) crítica hacia este objeto de estudio.

\section{Salidas y entradas}

Adentrarse gradualmente en la ciudad de Cali por la calle Trece de norte a sur, atravesando los barrios de Santo Domingo y Primero de Mayo, implica dejar atrás edificaciones de dos plantas a pie de calle y otear muros que cegando las calles encapsulan bloques de viviendas. Todo ello induce al observador a entender que el ecosistema urbano ha sufrido un cambio radical no solo en sus apariencias fisicas, sino también en sus moradores y las clases sociales de pertenencia. Percepción que se incrementa a medida que se accede con más intensidad a las zonas del sur de la ciudad. Este nuevo panorama habitacional se caracteriza por la poca presencia de flujos intensos y permanentes de peatones, así como por el diseño interno del barrio basado fundamentalmente en líneas rectas y previsibles, con amplias vías locales que permiten el flujo vehicular desembocando en otras de tipo colectoras e incluso a arterias principales de la ciudad. Es frecuente observar cómo en el interior de los barrios se han proyectado grandes zonas verdes centrales que se convierten en uno de los pocos espacios de interacción social. La casi ausencia de locales comerciales de proximidad, la ausencia de vías para ciclistas, la tendencia a cierta segregación y fragmentación con respecto a barrios circundantes y la presencia notable de centros comerciales que fungen como los espacios de sociabilidad preferidos convierten a estas vecindades en territorios excesivamente zonificados. 
Y ha sido en los últimos lustros cuando se ha producido la consolidación de esta expansión de la ciudad hacia el sur, constituyéndose en una nueva centralidad; es decir, el proceso por el cual se generan las condiciones objetivas para reconvertir en suelo urbanizable el que anteriormente no lo era y obtener rápidas plusvalías a partir de su edificación; para lo cual es indispensable invertir en infraestructura y equipamientos para convertir ese territorio en un área atractiva. El fruto de esa inversión ha ido encarnándose en la proliferación de nuevos barrios en cuya lógica se entrevé -en parteel modelo de condominio cerrado de alta gama (Janoschka, 2002; Martínez, 2016). ${ }^{4}$ Por un lado, estos barrios adquieren la forma de urbanizaciones de torres de apartamentos y casas unifamiliares caracterizadas por su acuartelamiento y por la existencia en su interior de piscina, áreas verdes, recreativas y zonas de parqueo (García y Peralta, 2016; García-Jerez, 2016); y por otro, son barrios pensados para ciertas clases medias emergentes, no tanto para las más altas. Ejemplos paradigmáticos de ello son los dos barrios seleccionados: La Hacienda y Valle del Lili (figura 1).

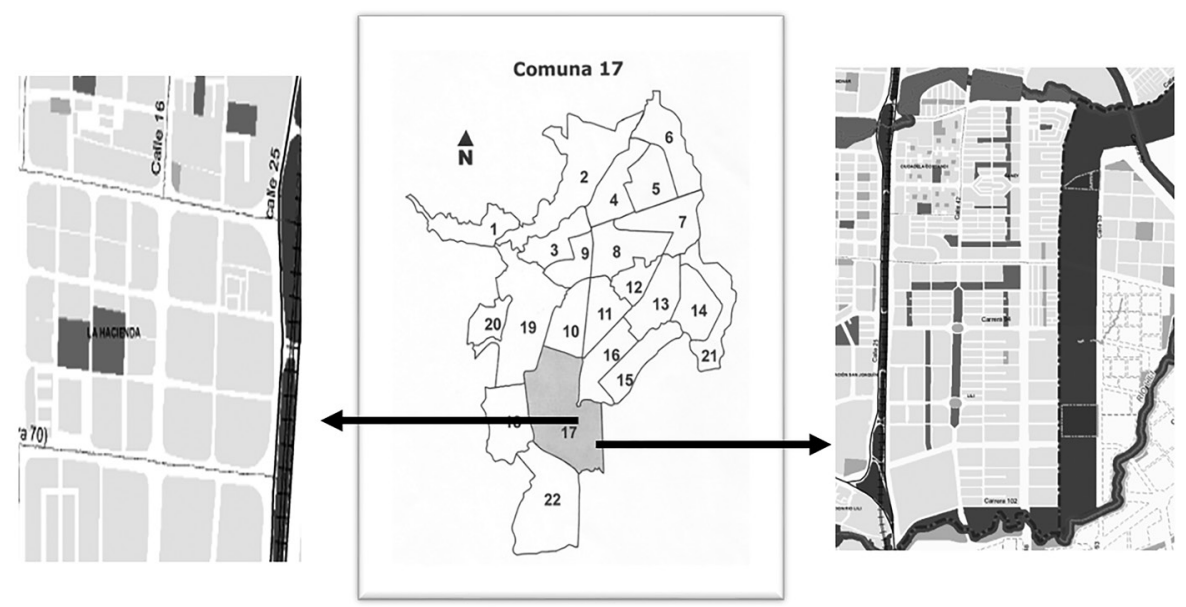

Figura 1. Mapa de la ciudad de Cali y de los barrios La Hacienda y Valle del Lili Fuente: Elaboración propia.

4 Para más información acerca de las dinámicas sociales de las urbanizaciones cerradas en Colombia, recomendamos consultar el número 21 de la revista Prospectiva, el cual está dedicado monográficamente a este tema. Recuperado de http://revistaprospectiva.univalle.edu.co/ 
¿Cuáles son, entonces, las prácticas de movilidad desplegadas por los residentes de los dos barrios seleccionados? Según los datos recogidos en la encuesta que se aplicó, los desplazamientos realizados se caracterizan porque el $46,6 \%$ de los vecinos realizan dos salidas al día, si bien el 43,3 decía hacer tres o más en una jornada. En ellos el vehículo más utilizado para dicha movilidad es el automóvil. Prácticamente un $70 \%$ dice utilizarlo; a diferencia del $25 \%$ de los residentes, quienes se desplazan en alguna modalidad de transporte colectivo. Tendencias que reflejan el componente de clase en la movilidad, ya que según la encuesta realizada por Cali Cómo Vamos (2015, p. 74) son los sectores que se autorreconocen pobres los que se desplazan tres veces menos en vehículo privado y los que usan más el nuevo sistema del MIO (48 \% en comparación con el $38 \%$ de los que no se consideran pobres). Por tanto, el automóvil se transforma en el transporte hegemónico, en la primera opción de movilidad. No en vano, el ratio de automóviles por hogares para los dos barrios seleccionados es el siguiente, según la encuesta propia: el $85 \%$ afirmaba disponer de automóvil en propiedad y por hogar, mientras que de ese $85 \%$, el 59,4 \% reconocía disponer al menos de dos o más automóviles.

La mayoría de los destinos de esos viajes tiene como objeto la propia zona sur de la ciudad (casi un $70 \%$ ), siendo sus principales direcciones los lugares vinculados con el trabajo, seguidos de los supermercados, centros comerciales y parques cercanos. Como destinos pocos demandados se encuentran los focalizados en la recreación y los culturales. Estos últimos apenas se acercaban al $3 \%$. Con respecto a los centros comerciales y supermercados, los desplazamientos hacia ellos están estrechamente vinculados con su condición de obligatoriedad, si bien debo matizar que, al menos para el primero de estos, su función no se limita a la de proveer de artículos de primera necesidad, sino que ofrece una amplia diversidad de espacios destinados al ocio que complementaría la propia salida. Centrándome en el tiempo recorrido al trabajo, por ser este el destino obligatorio más mencionado, el $53 \%$ de los residentes se demora entre 15 a 59 minutos, a diferencia del 5,4\% de aquellos que invertían menos de 15 minutos. En comparación con otras zonas de la ciudad, según los datos mostrados en el informe de 
2015 de Cali Cómo Vamos el tiempo medio para la zona sur era de 39,7 minutos, siendo el promedio general de 37. Esta misma encuesta también ofrece datos muy relevantes con respecto al tiempo invertido en los desplazamientos cotidianos en función del nivel socioeconómico auto-percibido (bajo/medio/alto) por los mismos encuestados: para aquellos en el nivel alto el tiempo es de 29,8 minutos, para los de los sectores medios es de 37,9 y para los de bajo ingresos es de 40,8 minutos (Cali Cómo Vamos, 2015). Por tanto, todo apunta a que el acceso a la movilidad está condicionado al menos por los recursos económicos de los que se disponga, los cuales determinan a su vez la cantidad del recurso tiempo invertido.

\section{Habitus ambulante}

Considero que estas prácticas, hábitos y costumbres de movilidad descritas están mediadas en parte por una lógica de la repetición inconsciente como la del cálculo por optimizar los costes del propio trayecto (Davidov, 2007); de ahí que para analizar esos comportamientos ambulantes se deba recurrir no solo a aspectos psicológicos e individuales, sino también a variables estructurales marcadas por las características socioeconómicas, educativas, étnico-raciales, de estatus, de género o, incluso, residenciales que atraviesan y configuran al propio sujeto. Todas estas variables definen las preferencias de esos sujetos en cuanto a la elección del transporte y la instauración de un modo corporal de movilidad que se expresa en la cotidianidad. También los sitúan en una posición determinada en el campo de la movilidad proporcionándoles un punto de vista particular que guía sus prácticas y representaciones, al mismo tiempo que les permiten clasificar y ser clasificados. Es lo que Pierre Bourdieu denomina el habitus; es decir:

[...] principios generadores de prácticas distintas y distintivas $[\ldots]$ pero también son esquemas clasificatorios, principios de clasificación, principios de visión y división, aficiones, diferentes. Establecen diferencias entre lo que es bueno y lo que es malo, 
entre lo que está bien y lo que está mal, entre lo que es distinguido y lo que es vulgar. (1997, p. 20)

En efecto, es a partir de la observación de su conducta social de movilidad, basada, por ejemplo, en la conducción de un medio de transporte, la de personalizarlo, la de seleccionar una ruta de tránsito, entre otras conductas, lo que configura un habitus particular (deudor de estructuras externas) que es interiorizado por un grupo y proyectado como imagen de pertenencia particular a una clase. Siguiendo a Bourdieu, ese habitus genera un estilo de vida, es decir, un "sistema de prácticas enclasadas y enclasantes” (Bourdieu, 1998, p. 113). En esas lógicas de movilidad, al igual que en otras lógicas tales como las económicas, religiosas o educativas, pueden localizarse pautas de acción aparentemente irreflexivas pero que obedecen a estructuras de pensamientos y acción regladas en función de las posiciones sociales y de las formas de distinción delimitadas entre clases sociales. Es por ello que las conductas móviles también han de ser consideradas un espacio social idóneo donde observar y analizar esas rutinas ${ }^{5}$ de desplazamiento que configuran, en última instancia, lo que he denominado un habitus ambulante particular. Si bien estas están configuradas por acciones, hechos fácticos o conductas observables, en ellas las representaciones sociales desempeñan un rol central por cuanto todos aquellos objetos y conductas que componen, en esta ocasión, el campo de la movilidad son revestidos por imágenes, significados y simbolos. Este andamiaje ideacional estructura la acción, siendo estructurada a su vez por esta; o como afirma el propio Emile Durkheim: “[...] todos los fenómenos [se refiere a las representaciones] tienen causas que los producen; pero, a su vez, ellos son causas de otros fenómenos" (2006, p. 4). Su cristalización -nunca estable- es producto no solo de la iniciativa individual, sino también de la interacción social y de los intereses existentes. De ahí que lo ideacional pueda ser considerado uno de los vehículos y dispositivos más relevantes en orden a indagar la intersubjetividad social, así como la subjetividad individual. De nuevo retomando a Durkheim, esas representaciones se instauran como la "verdadera realidad social $[. .$.$] no$ sólo están en nosotros, sino que, como son un producto de experiencias

5 Fue Emile Durkheim quien definió el hábito como un mecanismo o dispositivo que por su propia naturaleza rutinaria e irreflexiva dificultaba el cambio social (Camic, 1996, p. 1057). Sin embargo, han sido autores como Carrus, Passafaro y Bonnes (2008), Davidov (2007) y Gärling y Axhausen (2003) quienes más y mejor se han centrado en su análisis. 
repetidas, reciben de la repetición, y de la costumbre producida por ella, una especie de ascendiente y autoridad" (1995, p. 73).

En efecto, en mi opinión las representaciones sociales revelan los modos de aprehensión de los acontecimientos de la vida social a partir de la puesta en circulación de símbolos, significados, imágenes, discursos o cualquier otro repertorio lingüístico o universo semántico a partir de instituciones e interacciones sociales que, en un proceso de interiorización social y psicológico, devienen en un modelo que permite el desenvolvimiento en la realidad social. Son, por tanto, un conocimiento práctico. Como bien afirma la psicóloga Denise Jodelet (1986), las representaciones sociales son "imágenes condensadas de un conjunto de significados; sistemas de referencia que nos permiten interpretar lo que nos sucede, e incluso dar un sentido a lo inesperado, categorías que sirven para clasificar las circunstancias, los fenómenos y a los individuos con quienes tenemos algo que ver" (pp. 472-473). Así pues, las funciones de las representaciones sociales podrian sintetizarse en clasificar y explicar la realidad; por tanto, en definir identidades, en orientar prácticas sociales y en justificar comportamientos.

Retomando el rol de lo ideacional en este fenómeno de los desplazamientos diarios y la premisa inicial, me he formulado algunos interrogantes en orden a examinar la relevancia de las representaciones sociales en la práctica móvil de los residentes de ambos barrios. Interrogantes tales como: ¿cuáles son las representaciones sobre los diferentes medios de transporte utilizados? ¿Cómo estas condicionan la elección y práctica de movilidad cotidiana? ¿Y cuál es la posible relación entre una morfología barrial particular con las representaciones y las prácticas de movilidad de sus residentes?

\section{De desiderátum y mixtificaciones}

En orden a responder esas preguntas, y teniendo en consideración las nociones de Durkheim y la definición de Jodelet, he clasificado 
las imágenes, opiniones e ideas articuladas por los vecinos de los barrios seleccionados en tres representaciones diferentes.

1. La primera de ellas, que he denominado como el desiderátum de la movilidad sostenible, está estrechamente ligada con ese fenómeno que desde hace más de una década ha situado al transporte y, más en general, a la movilidad cotidiana como uno de los temas centrales de la arena pública; en particular lo relativo a la eficiencia en el desplazamiento diario de la masa de trabajadores, pero también en lo concerniente a la contaminación y polución producidas por los vehículos motorizados. Esta centralidad se debe en buena medida a la implantación de lo que se ha denominado Bus de Tránsito Rápido en ciudades tales como Curitiba, Bogotá y Quito (Pardo, 2009); también en Cali, con el Sistema de Transporte Masivo (MIO) inaugurado en noviembre del 2008. El efecto causado en las diferentes ciudades por su implementación tanto en el plano urbanístico -al reorganizarse espacialmente parte de la ciudad-como en el social -al ofrecerse un nuevo medio de transporte de carácter colectivo y masivo- ha contribuido a que un segmento importante de los residentes entrevistados concibieran este sistema como uno de los más idóneos para favorecer la movilidad cotidiana en Cali junto con la construcción de un metro convencional), aunque invocando a la necesidad de introducir sustanciales modificaciones en este: "no sé, un MIO pero con más buses y más alimentadores, más rutas y que uno pueda parar donde necesite" (A. C., 29 años, periodista, residente en La Hacienda); "es que el MIO tiene... no es malo del todo, el MIO tiene cosas buenas. Falta de pronto se preocupen más por optimizar el servicio, por la seguridad [...] yo no sé qué será lo que falta, pero el MIO no es malo" (J. D., 50 años, ama de casa, residente en Valle del Lili); o, por último, "yo creo que un sistema masivo pero bien planeado y que tomara precaución de todo a futuro; es decir, que no dejen espacios en blanco, sino que hagan primero una planeación completa de todo lo que va a llevar el proyecto para evitar después cuando ya esté funcionado errores" (L. L., 29 años, músico, residente en La Hacienda). 
Así mismo, y si bien algunos entrevistados afirmaban que el perfil de los usuarios del transporte colectivo formal cubría un amplio espectro (como nos decía un entrevistado: "mi impresión es que todo el mundo utiliza el MIO porque es un modelo impuesto. Desde que empezaron a sacar el sistema de busetas, el MIO es la única posibilidad" (N. C., 30 años, estudiante universitario, residente en La Hacienda), lo cierto es que existe un reconocimiento de soslayo acerca de que este medio de transporte está siendo utilizado principalmente por los sectores más populares, entre ellos destacan los trabajadores (principalmente mujeres) y los estudiantes; en definitiva "los que no tienen carro, los que no tienen moto y los que les da pereza la bicicleta" (S., 28 años, estudiante de ingenieria, residente en Valle del Lili). Por tanto, esta percepción clasista del MIO corrobora el poco uso frecuente de los residentes de los barrios seleccionados (solo un 14,2\% de los encuestados). ${ }^{6} \mathrm{De}$ hecho, aquellos que perciben un componente interclasista de MIO no es tanto por su experiencia personal sino porque conocen a un amigo o compañero de trabajo que se desplaza o se ha desplazado en él. Esto confirma esa especie de obligación social por reconocer a este sistema como el más apropiado para el conjunto de la sociedad. Sin embargo, cuando entra en liza la elección individual, cada residente, y según los datos obtenidos, parece que se decanta por resolver sus intereses de movilidad a través del uso del automóvil. Esto nos conduce a pensar en la existencia de una tendencia hacia la conducta fundamentada en una colectivización extrapersonal del medio de desplazamiento y una individualización personal en la satisfacción de la movilidad cotidiana.

En similar situación se encuentra la bicicleta como medio de transporte. La ola mediática y activista que ha situado a este medio de transporte como un ideal en el desplazamiento urbano utilitario también tiene su correlato en América Latina (Baumann et al., 2013)

6 En términos generales la práctica de movilidad de los residentes de ambos barrios es similar. Sin embargo, se han detectado algunas diferencias, como por ejemplo que en La Hacienda el 81,8\% decía preferir caminar, mientras que en Valle del Lili este porcentaje descendía hasta el 72,7 \%. Del mismo modo, en el primer barrio el 58,2 \% afirmaba acudir con mucha frecuencia al parque (práctica que se suele hacer en automoción a pie), mientras que en el segundo descendía al 16,7 \%. Así mismo, mientras que un $81,7 \%$ de los encuestados del barrio La Hacienda afirmaba tener un automóvil, en el Valle del Lili este porcentaje aumentaba hasta el 94,3 \%. Estas diferencias podrían explicarse, entre otras cuestiones, por el carácter sociourbanístico más consolidado del barrio La Hacienda y su mayor integración en la trama urbanística de la ciudad. 
y en particular en Cali; la puesta en marcha de ciclovías, la construcción todavía precaria de una red de ciclorrutas en la ciudad y la aparición de un movimiento de ciclistas urbanos han situado a la bicicleta en una posición simbólica relevante, al menos en las políticas de movilidad en Cali (Mosquera-Becerra, 2016). Sin embargo, me pregunto si este es contemplado como una alternativa real a la movilidad cotidiana o es solo producto de esa ola mediática. Lo cierto es que si bien muchos de ellos manifestaban la necesidad de mejorar la infraestructura ciclista en la ciudad, así como lo relativo a la protección del usuario referente a la inseguridad vial y personal, la mayoría de ellos no concebía la bicicleta necesariamente como un medio de transporte diario sino más bien como un dispositivo lúdico y deportivo: "lo mejor [es] compartir con la familia, hacer deporte, disfrutar de un domingo en familia, el aire, la frescura, [sale] uno de la monotonía” (A. G., 38 años, comerciante, residente en La Hacienda); H., abogado de 41 años, vecino de Valle del Lili también aludía algo similar: "[es] más desde el punto de vista deportivo, no desde como un medio de transporte que satisfaga el tema de la movilidad", o como nos reconocía A. R. (43 años, gerente, residente en La Hacienda) al preguntarle si conocía vecinos que utilizaran la bicicleta de modo utilitario: “¡Muy pocos! Yo conozco los que utilizan bicicleta para salir a hacer deporte. Es más, ahora de la unidad salieron siete, compraron bicicleta y están con un tema de moda de que 'vamos para no sé dónde"').

Sin duda cuestiones relacionadas con esa inseguridad, así como la falta de accesibilidad influyen, pero también la percepción de que la bicicleta es un medio asociado a lo deportivo y recreativo. Esto contrasta con el uso dado por los sectores más populares y afro de la ciudad, para quienes la bicicleta se convierte en el principal dispositivo de movilidad cotidiana al no poder acceder a un automóvil (Mosquera-Becerra, 2016). Por tanto, el medio que satisface mejor las necesidades de desplazamiento de los residentes de sendos barrios es el automóvil privado, a pesar de que muchos de sus viajes tienen como destino la zona sur (casi un 70 \%), un área relativamente próxima a sus residencias. Este medio de transporte, según ellos, les garantiza comparativamente mayor rapidez, disponibilidad y comodidad. 
2. La segunda representación la he denominado el automóvil como dispositivo eficiente. Es este medio de transporte, el automóvil, el que está experimentando un aumento considerable en cuanto al número de sus unidades en circulación. Esto es producto de las políticas crediticias de incentivación de compra de vehículos y de la planificación urbana donde todavía se invierte en una red vial cuyo fin es acoger cada vez a más automóviles, fomentado a su vez por un sector privado que está depositando parte de su capital en ello en aras de rentabilizarlo. ${ }^{7}$ De hecho, según algunos de los informes elaborados por Cali Cómo Vamos (2012), ya se anunciaba el incremento en la ciudad del parque automotor en un $62 \%$ durante el periodo de 2000 a 2009. Así mismo, habría que sumar la ineficacia de alternativas de movilidad como son los ya mencionados sistema de bus rápido y red de ciclorrutas; por tanto, en esa concepción hipercalculada del desplazamiento diario (Nowotny, 1994) como ir al trabajo, de compras a centros comerciales y supermercados próximos e incluso transitar por el barrio, es el automóvil el que satisface esas necesidades; lo que es producto de la "cultura automovilística" de las sociedades actuales, tal y como nos sugieren Sheller (2004) y Urry (2004). Sin embargo, y más allá de estos aspectos materiales, debo destacar el valor y la función simbólicos que juega el automóvil no solo en Cali sino también en otros contextos. Ascender socialmente y pertenecer a una clase media requiere de dispositivos con los que el individuo se enclase. Uno de ellos es la propiedad de un automóvil, y en particular su modelo, puesto que este funciona no solo como marcador de prestigio sino también como identificador de clase tanto en el plano psicológico como en el social. Circunstancia que se aprecia especialmente en Cali puesto que su acceso está en parte todavía restringido económicamente. Según el informe elaborado por la Red de Ciudades Cómo Vamos (2015), en el que se comparan 14 ciudades colombianas, la tasa de automóviles en Cali es de 17 por cada 100000 habitantes (2012, p. 74), pasándose de 373936 automóviles en el 2005 a 504653 en el 2010. Esto significa un incremento del $35 \%$ del parque automotor en esos últimos cinco años (Cámara de Comercio de Cali, 2012). Datos que,

Para más información recomiendo consultar la siguiente web: https://www.bbvaresearch.com/public-compuesta/ situacion-automotriz-colombia-2016/ 
específicamente en los dos barrios analizados, ascienden al 88,5\%, los cuales decían poseer uno o más vehículos. Porcentaje que apunta a la existencia de una alta concentración de automóviles en este tipo de vecindades, lo que nos remite a los segmentos de clases medias y altas, mestizos y blancos. Este panorama se ve corroborado en las palabras de algunos de nuestros entrevistados cuando nos confirmaban que habian adquirido un nuevo automóvil en los últimos cinco años bajo la idea de la renovación: "Por cambiar, por renovar y porque salía más económico comprar un carro nuevo que tener uno viejito" (G. H., 38 años, psicóloga, residente en Valle del Lili) o como nos lo explicaba L. L. (28 años, músico, vecino de Valle del Lili) en relación con los hábitos de compra de sus padres: " yo desde que conozco a mis padres siempre han estado cambiando [de carro]; o sea no son de quedarse con un carro diez años, sino que buscan digamos salir con un carro nuevo".

Sin embargo, y más allá de ese componente de estatus, habría que sumarle la idea de libertad (disponibilidad total) conjugada al mismo tiempo con la de seguridad, tal y como nos lo transmitían nuestros entrevistados: "que uno maneja los tiempos; usted maneja la velocidad que usted quiera y depende del compromiso que tenga" (A. R., 43 años, gerente, residente en La Hacienda); "uno va directo al sitio donde va, no tiene que estar caminando ni buscando buseta si lo lleva, o que el alimentador, que una va a donde va y ya" (A. C., 29 años, periodista, residente en La Hacienda); "[lo mejor de conducir automóvil] la comodidad y la seguridad, porque si una moto se accidenta, el primero que recibe el golpe es el conductor y el parri1lero" (L. L., 56 años, residente en La Hacienda). Así mismo, en un contexto donde la inseguridad objetiva y subjetiva es bastante alta, disponer de un automóvil garantiza ese umbral de seguridad al conceder un espacio individual no compartido con una masa extraña, anónima y heterogénea como la que se da cita en las estaciones de los buses. Henderson denomina a este fenómeno de "automovilidad secesionista" (mencionado en Ureta, 2009), en el sentido, nos dice Ureta, "de que el automóvil es utilizado como un medio para aislarse de un contexto urbano percibido como potencialmente peligroso y/o dañino" (2009, p. 88). 
3. La última de las representaciones la he llamado de la mixtificación de la conducción. Tal y como ya comenté, son las clases medias y altas las que muestran un mayor uso del automóvil, lo que está ocasionando, por un lado, el aumento del parque automovilístico, y por otro, la pérdida de contextos interclasistas como sería la utilización de medios de transportes colectivos masivos. Quizás podría aventurarme a apuntar a cierta diferenciación clasista en los desplazamientos en los barrios seleccionados o, si se desea, en la acumulación del capital de motilidad (Kaufmann et al., 2004; García-Jerez, 2016). Esa tendencia de las clases medias y altas está basada tanto en el conocimiento práctico de las experiencias de movilidad cotidiana -ya que el automóvil satisface sus necesidades en cuanto disponibilidad y eficiencia-, como en la interiorización de representaciones que mixtifican al automóvil y estigmatizan, por ejemplo, al MIO. Podría inferir que, en efecto, si bien la mayoria de entrevistados nos trasladaban una idea de confort con respecto al automóvil, también nos manifestaban que la práctica diaria del manejo del automóvil en Cali dista mucho de llevarse a cabo de un modo ideal. De sobra son conocidos los problemas y obstáculos que aparecen en el ejercicio de la conducción. Algunos entrevistados se expresaban al respecto de la siguiente forma: "La movilidad, los trancones, la imprudencia de la gente, la falta de cultura en el manejo, el estrés que se maneja cuando se conduce" (C. R., 43 años, gerente de una compañía, residente en La Hacienda); "manejar carro en la ciudad es un caos, es un caos impresionante, porque hay muchos trancones, no hay vías para manejar aquí en Cali" (A. G., 38 años, comerciante, residente en La Hacienda); G., mujer y residente del Valle del Lili, argumentaba lo siguiente con respecto a la movilidad de su barrio: "Las vias en general son buenas, pero pienso que debería haber más salidas, pues hay pocas y por los trancones son imposibles"; o el señor A. (48 años, asistente de mantenimiento, residente en Valle del Lili) cuando me reconocía: "A veces se siente uno como con nervios por tanta cantidad de carros que hay, entonces va uno como un poco asustado". De ahí que me atreva a afirmar que la percepción acerca de la práctica rutinaria de la conducción del vehículo privado se decanta en última instancia hacia una cierta mixtificación, puesto que dulcifica parcialmente los efectos negativos corporales y mentales asociados a ella. Esta condición 
ambigua del automóvil queda perfectamente retratada en las palabras de los siguientes entrevistados: "Depende de la hora, en la hora pico pues uno se estresa por los trancones, pero claro a mí me gusta manejar mi carro. Mi independencia, que voy aquí y allá" (V. M., 31 años, diseñadora y ama de casa, residente en La Hacienda); "lo mejor es que uno llega rápido y lo peor es la inseguridad y el trancón” (G. H., 38 años, psicóloga, residente en Valle del Lili); “... porque tú entras y sales a la hora que quieras, aunque te chupas tráfico y te toca aguantarte el tráfico que hay a determinada hora, pero te ofrece comodidad que no te ofrece ni la bicicleta ni el transporte público" (S., 28 años, estudiante de ingeniería, residente en el Valle del Lili); "lo peor los trancones, definitivamente; lo mejor es un tema de comodidad, lo principal, y pues por llegar más rápido a donde necesita" (H., 41 años, abogado, residente en Valle del Lili).

\section{Hegemonia y emancipación}

Fue Moscovici (2000) quien, reactualizando los planteamientos de Durkheim, enfatizó el carácter dinámico de la configuración de las representaciones sociales y su función dentro de una sociedad. Para ello estableció una tipología de representaciones en virtud de su consenso e interiorización social. Un primer tipo lo denominó "hegemónico", que es homologable a la colectiva de Durkheim, por cuanto es la representación que prevalece en una sociedad dado que posee una dimensión coercitiva; un segundo tipo lo calificó como "emancipado", que es la representación configurada expresamente en el seno de un determinado grupo social; y un tercer tipo al que llamó "polémico", que es la representación que surge igualmente en el seno de grupos pero que es producto de una situación conflictual y que funciona como un dispositivo con el cual expresar un discurso contrahegemónico o disidente (Moscovici, 1988, p. 32).

Partiendo de esta propuesta clasificatoria y teniendo en consideración las tres representaciones resultantes de la investigación (la del desiderátum de la movilidad sostenible, la del automóvil como 
dispositivo eficiente y la de la mixtificación de la conducción), considero que las dos primeras son productos de un contexto actual con una fuerte connotación paradójica. Si, por un lado, desde el ámbito gubernamental se ha puesto en circulación un discurso donde la movilidad ha quedado adjuntada a la noción de sostenibilidad, implicando que muchas de las políticas públicas en este terreno se justifiquen en ello, por otro lado, desde la industria automotriz en colaboración con lo gubernamental se continúa fomentando el uso -a veces indiscriminado- del automóvil, bien a partir del abaratamiento del precio del vehículo gracias a los tratados internacionales de libre comercio y a las políticas facilitadoras del crédito bancario; bien con los subsidios a la compra de carburante y a las grandes inversiones en la construcción de infraestructura vial y, por contra, la poca ayuda y prestación a los sistemas de transportes colectivos o, incuso, su parcial privatización (Figueroa, 2001). Si bien estos dos vectores ocasionan una tensión y una contradicción en términos que se expresan en las representaciones sociales de los individuos analizados, ambas representaciones las calificaría de hegemónicas, siguiendo la tipología propuesta por Moscovici.

Con respecto a la tercera, la de la mixtificación de la conducción, esta, dada su naturaleza práctica, la consideraría como "emancipada", por cuando da cuenta de las especificidades de un sector social particular que sitúa al automóvil en un ideal de movilidad -o al menos en posición preferencial- a pesar de reconocer sus deficiencias y ambigüedades. De esta forma se autoabastecen de un medio de transporte que en cierto modo satisface sus necesidades. Es por ello que, en palabras de Kesselring (2008), esta representación formaría parte del "mobility management" de los sujetos analizados; es decir, de la capacidad estratégica que poseen en orden a adaptarse a una situación de movilidad dada. En esta ocasión, esta estaría condicionada por la percepción de una cobertura objetivamente deficiente del transporte público, por el predominio de un habitus ambulante configurado por las dos últimas representaciones -y que deliberadamente fomenta la compra y uso del automóvil-, por la sensación de inseguridad, así como por la morfología urbanística de los barrios fuertemente zonificados y fragmentados. De este modo hago mía la tesis de Froud (mencionado 
en Ureta, 2009) de que las clases medias (para él serían las populares) han interiorizado el uso del automóvil no solo por cuestiones de estatus o autoexpresión, sino también por necesidad objetiva y subjetiva. Estas circunstancias les impulsan, en última instancia, a formar parte de (pero también a espolear) una lógica automovilística ya de por sí expansiva y de la que ellos se muestran por ahora como sus principales protagonistas.

\section{Referencias}

Anta, J. L. (2015). El automóvil: genealogia de un objeto de poder. methaodos. revista de ciencias sociales, 3(1), 93-106.

Barthes, R. (1999). Mitologías. México DF: Siglo XXI Editores.

Baumann, C., Bojacá, M., Bambeau, M. y Wanner, Z. (2013). Biciudades: un estudio regional acerca del uso de la bicicleta como medio de transporte en América Latina y el Caribe. American University School of International Servicies. Recuperado de http://www.vanguardia.com/sites/default/files / informe_uso_de_las_bicicletas.pdf

BBVA Research. (2010). Latinoamérica Situación Automotriz. Diciembre 2010. Recuperado de https://www.bbvaresearch.com/KETD/fbin/mult/ ESTAULT_14122010_tcm346-239499.pdf?ts=1742012

Bourdieu, P. (1997). Razones prácticas sobre la teoría de la acción. Barcelona: Anagrama.

Bourdieu, P. (2012). La distinción. Criterios y bases sociales del gusto. Madrid: Tauro.

Cali Cómo Vamos. (2012). Informe de calidad de vida en Cali, 2011. Cali Cómo Vamos. Recuperado de http://media.wix.com/ugd/ ba6905_7ced36ecd5b24b6e962430f865254c37.pdf 
Cali Cómo Vamos. (2015). Informe de calidad de vida en Cali, 2014. Cali Cómo Vamos. Recuperado de http://media.wix.com/ugd/ ba6905_906136a6aaca4cc59e683051c8d7ceff.pdf

Cámara de Comercio de Cali. (2012). Movilidad: un reto para una Cali con futuro. Edición N. ${ }^{\circ}$ 144. Recuperado de http://www.ccc.org.co/movilidad-un-retopara-una-cali-con-futuro

Camic, C. (1996). The matter of habit. American Journal of Sociology, 91(5), 1039-1087.

Carrus, G., Passafaro, P. y Bonnes, M. (2008). Emotions, habits and rational choices in ecological behaviours: the case of recycling and use of public transportation. Journal of Environmental Psychology, (28), 51-62.

Davidov, E. (2007). Explaining habits in a new context: the case of travel-mode choice. Rationality and Society, 19-315.

Durkheim, E. (1995). Las reglas del método sociológico. Barcelona: Altaya.

Durkheim, E. (2006). Sociologia y Filosofia. Granada: Editorial Comares.

Figueroa, O. (2001). Políticas de desarrollo y politicas de transporte urbano. Coherencias y contradicciones. En F. Carrión (Ed.), La ciudad construida. Urbanismos en América Latina (pp. 377-390). Quito: Flacso.

Garcia, F. y Peralta, M. (2016). Las urbanizaciones multifamiliares cerradas y su entorno urbano: una nueva geografia simbólica en la ciudad de Cali (Colombia). Revista EURE - Revista De Estudios Urbano Regionales, 42(126).

Garcia-Jerez, F. (2016). La movilidad socio-espacial desde la teoría de Pierre Bourdieu: capital de motilidad, campo de movilidad y habitus ambulante. Sociedad y economía, 31, 15-32.

Gärling, T. y Axhausen, K. W. (2003). Introduction: habitual travel choice. Transportation, 30, 1-11. 
Giucci, G. (2007). La vida cultural del automóvil. Rutas de la modernidad cinética. Buenos Aires: Universidad Nacional de Quilmes - Prometeo Libros.

Janoschka, M. (2002). El nuevo modelo de la ciudad latinoamericana: fragmentación y privatización. Revista Eure, XXVIII(85), 11-29.

Jodelet. D. (1986). La representación social: fenómenos, conceptos y teoría. En S. Moscovici (Ed.), Psicología Social II (pp. 469-494). Barcelona: Ediciones Paidós.

Kaufmann, V., Bergman, M. y Joye, D. (2004). Motility: Mobility as Capital. International Journal of Urban and Regional Research, 24(4), 745-756.

Kesselring, S. (2008). The mobile risk society. En W. Canzler, V. Kaufmann y S. Kersselring (Eds.), Tracing mobilities. Towards a cosmopolitan perspective (pp. 77-101). Farnham: Ashgate.

Marinetti, T. (1909). El Manifiesto Futurista. Le Figaro. Recuperado de http:// webs.advance.com.ar/pfernando/DocsIglCont/Marinetti-manifiesto.html

Martínez, P. (2016). El conjunto residencial cerrado como tipología urbanística instrumentalizada por la financiarización. Prospectiva. Revista de Trabajo Social e intervención social, 21, 25-55.

Moscovici, S. (1988). Notes towards a description of social representations. European Journal of Social Psychology, (18), 211-250.

Moscovici, S. (2000). Social Representations. Explorations in Social Psychology. Cambridge, Uk: Blackwell Publishers Ltd.

Mosquera-Becerra, J. (2016, jul-dic). El transporte en bicicleta: consolidando inequidades en las calles de Cali, Colombia. Sociedad y economía, (31), 95-120.

Motavalli, J. F. (2001). Froward drive: the race to build 'clean' cars for the future. San Francisco, US: Sierra Club Books.

Nowotny, H. (1994). Time. The modern and postmodern experience. Cambridge, US: Polity Press. 
Pardo, C. (2009). Los cambios en los sistemas integrados de transporte masivo en las principales ciudades de América Latina. Santiago de Chile, Chile: CEPAL.

Red de Ciudades Cómo Vamos. (2015). Informe de calidad de Vida Comparado en 14 Ciudades de Colombia. Boletín $N .^{\circ} 6$.

Sennet, R. (2007). Carne y piedra. El cuerpo y la ciudad en la civilización occidental. Madrid: Alianza Editorial.

Sheller, M. (2004). Automotive emotions: Feeling the car. Theory, Culture \& Society, 21(4/5), 221-242.

Sheller, M. y Urry, J. (2000). The city and the car. International Journal of Urban and Regional Research, 24(4), 737-757.

Steer Davies Gleave. (2015). Producto 4. Indicadores Encuesta de Movilidad. Cali: Metro Cali.

Ureta Icaza, S. (2009). Manejando por Santiago. Explorando el uso de automóviles por parte de habitantes de bajos ingresos desde una óptica de movilidad sustentable. Revista Eure, XXXV(115), 71-93.

Urry, J. (2004). The system of automobility. Theory, Culture \& Society, 21(4/5), 25-39.

Zeller, T. (2011). Staging the Driving Experience: Parkways in Germany and the United States. En M. Hvattum, B. Brenna, B. Elvebakk y J. Kampevold J. (Eds.), Roads and Landscapes (125-138). Farnham: Ashgate.

\section{Cómo citar este artículo}

García Jerez, F. A. (2018). Entre cuatro ruedas: lógica automovilística y barrios semicerrados en la ciudad de Cali (Colombia). Universitas Humanística, 85, 101-123. https://doi.org/10.11144/Javeriana.uh85.ecrl 